\title{
Usability Assessment of an Integrated Cataloging and Metadata Services: an Exploratory Study of the OCLC Connexion System*
}

\author{
통합 목록/메타데이터 서비스의 유저빌러티 평가: \\ OCLC Connexion 시스템에 대한 연구
}

이정미(Jeong-Mee Lee)**

\begin{abstract}
The goal of this study was to examine the relationships between usability and the searching experience, and to uncover where an integrated cataloging and metadata system lay the usability problems of its primary users, catalogers. This study showed that the most important aspect of usability in Connexion lay in the experience of information retrieval system. Also, it showed there are seventeen usability problems to be improved in Connexion. Needless to say, it is most important to note that usability is not an exclusive goal of such an integrated cataloging and metadata system. Other goals such as quality of catalogs, and the reliability of its cataloging and metadata system are equally its concern. This study also suggested more testing on diverse cataloging systems and specific user groups, especially catalogers.
\end{abstract}

\section{초 록}

이연구는통합목록/메타데이터시스템으로전세계에광범위한서비스가제공되고있는O CL 의 Connexion 시스템에 관한 유저빌러티를 실험한 연구이다. 유저빌러티실험은 상업적인 성공을 달성하기 위한 기업들의 노 력의 하나로써 시작되었으며 문헌정보학에는 특정한 정보 검색 시스템이 자신의 이용자들에게 좀 더 나은 서 비스를 제공하기 위해 시스템 인터페이스를 개선시키고자하는 노력의 일환으로 도입되어 사용되어 왔다. Connexion 서비스는 기본적으로 MARC 기준을 바탕으로 인코딩 되어 메타데이터 서비스를 통합하여 제공 하는 대표적인 통합 목록/메타데이터서비스로 알려져 있다. 실험 전반을 통해서 이용자의 실험과정이 녹화 분 석 되었으며, 6 개 영역 17 가지 사항의 유저빌러티 문제점들이 파악되었다. 또한 마지막으로 17 가지 사항들 에 대한 각각의 개선책들이 조심스럽게 제안되었다.

키워드: metadata, usability, system evaluation, human computer interaction 메타데이터, 유저빌러티, 시스템평가, $\mathrm{HCl}$

\footnotetext{
* 이 논문은 Florida State University 대학원 박사학위논문의 일부를요약한 것임.

** 서울여자대학교 문헌정보학과 조교수(jmlee@ swu.ac.kr)

논문접수일자 :2007년 11월 25일

게재확정일자 :2007년 11월 25일
} 


\section{Introduction}

The rapid growth and dissemination of online information resources, such as the World Wide Web (Gray 1997), has caused the concept of metadata to mean different things to different infor mation communities. Fundamentaly, metad at a is desigred to support int er act ion bet ween an end- user and an online retrieval system, providing users access to the information in the system by labeling its contents consistently regardless of the format of the information object. Interest in metadata has increased significantly in the emerging digital library context since the effective organizaion of networked information clearly depends on the effective management, organizdion, and control of metadata (Bur nett, Ng and Park 1999).

\subsection{The Metadata}

Although the term metadata emerged along side the rapid growth of the Internet, the foundation of the met adata concept is simply" data about data" (Wendler 1999). Thus, catalogs which have for centuries led end- users to data in traditional library environ ments can be considered met adata. Met adata standar ds are ways of structuring content, and this content is held by and delivered by one or more carriers such as various markup languages to MARC (Chapman 2002). Library catalog is one form of metadata, involving specific processes utilizing tools like the Anglo- A merican Cataloging Rules and USMARC.

For purposes of this study, metadata is oper ationally defined as: data that characterize source data, describe their relationships, and support their discovery and effective use(Burnett, Ng and Park 1999).

The traditional library catalog index card is a classic example of metadata, and a MARC (MAchine Readable Catalog) record is the equivalent example for automated cataloging workplaces. The author, title, DDC (Dewey Decimal Classifuation), etc., are me adata elements within a clearly def ined metadata scheme (Shabajee 2002). Even if these elements have different formats of description, it is not difficult to accept that each of the elements is part of a larger met adata syst en. Catabging and me adat a are essential keys to the actualization of Digital Library construction. Current digital libraries may be understood as very complicated systems involving various technical issues and tools. Because of the complicated nature of such libraries, many technical problems 
Usability Assessment of an Integrated Cataloging and Metadata Services:an Exploratory Study of the OCLC Connexion System193

have arisen from atempts to join cortr ary digital repositories. The efforts of computer science and information professionals to con duct usabilty testing to improve var ious interfaces and products may eventually contribute to the construction of a successful Digital Library .

\section{Usability Testing}

The evaluation of infor mation systems has been a widely discussed subject in the Infor mation Science (IS) It er ature. No consensus has emerged, however, on the best means for conceptualizing and oper ationalizing such evaluations (J anes 1994; Zmud and Boynton 1991). Usability testing has become a popular means for evaluating the effectiveness of information systems from the u ser's point of view. For several decades before usabilty testing appeared, relevance and user satisfaction were the two most prominent measures for user-based performance evaluations of information systems (Gluck 1996).

The International Standards Organization (ISO, DIS and 9241-11) defines usability as the extent to which a product can be used by specifed goals with effectiveness, efficiency and satisfaction in a specified context of use" (p.10). As common sense would indicate, usability typically focuses on how end users interact with a certain product or system as they perform actual tasks. With roots in computer science and engineering, usability testing has been applied most directly by reseachers and pract itioners seeking a use - centered approach in system and product design (Campbell 2001). This user- centered approach has been called many names, such as user - cettered design, ergonom ics, Human- Computer Inter action ( $\mathrm{HCl})$, and human factors and usability engineering.

For purposes of this study, usability testing is operationally defined as:

A method that tests how a user interacts with a system. The participant is given a list of pre- defined tasks to accomplish using the system and asked to" think out loud" about their thoughts, reactions and feelings(Campbell 2001).

Since the system and the end user may be regarded as the two most important factors in LIS research, usability testing is an important measurement tool for evaluating an information system. 


\subsection{Issues in the Metadata and Usability}

A significant amount of research involving metadata has been con ducted since 1997. A good deal of this research has focused on crosswalks, frameworks and supermetadata issues. In addition, issues related to the practitioner's use of metadata concepts, the application of metadata to empirical studies, and metadata and commercialization of the Internet have appeared more frequent ly in metadata studies (Burnett and Lee 2000).

A mong the many met adata standar ds, MARC is a traditional met adata structure that has been widely adopted by the library community. First introduced in the 1960s for the exchange and communication of bibliographic data, MARC has been expanded to facilitate the communication and exchange of many formats of information, such as books, sound recordings, and even World Wide Web publications. MARC fields and subfields contain various types of bibliographic information. Its comprehen sive scope and the availabilty of a wide range of metadata elements have made MARC one of the most distinguished features in the library environment.
The Dublin Core metadata element set was the outcome of a workshop soon sored by OCLC and the National Center for Supercomputing Applications (NCSA) in 1995. Subsequent workshops have extended the scope of the Dublin Core effort. Dublin Core is intended to be a basic collection of metadata elements - a lingua franca for met adata (Milstead and Feldman 1999). The Dublin Core development effort is still ongoing and is ex peded to cont inue indefin itely.

U sability may be a collective term for all aspects of an activity's performance that can be affected by the use of technology (Whiteside, Bennett and Holtzblatt 1988). The individual aspects are known as usabilty factors or atrbutes and are evaluated together to measure a product's usability (Campbell 2001).

\subsection{Usability Testing Design}

Since the ultimate goal of this study is to evaluate the usability of a current integrated cataloging and met adata ser $v$ ices system, it is necessary to clarify how the usability testing will be executed in this study.

A number of studies have introduced the creation and use of specifd metadata systems, however, improvements to metadata systems can best be ach ieved 
through the consistent maintenance of the systems. In order to make metadata sy stems max imally effective, infor mation professionals must resolve some key questions such as deciding how much is enough and how much is too much in regards to the metadata element structure (Gilliland- Swetland 1998). They must also improve the usefulness of the existing metadata systems in order to better serve users. Usability testing may provide a direction for the creation and maint enance of metada $a$ systems. Even though it may not be possible to reveal the perfect metadat a element structure at this stage, usabilty testing can provide a starting point for improvement.

This study uses three prominent fadors in usability testing: effectiveness, efficiency, and user satisfaction.

( Effectiveness in usability testing looks at whe her users can accompl i \$ tasks completely and accurately. Indicators of effectiveness in this study include the qual ity of solutions achieved and number of errors encountered.

(1) Efficiency in usability testing analyzes the amount of resources used to complete tasks ef fectively. Indic ators of efficiency of this study include task completion time and number of keystrokes.

(] Satisfaction deals with a user's attitude towards the product. It will be measured by a questions that the researcher will provide at the end of the session.

These three prominent factors of usability will be compared with the searching experience of users to see the relationship between each factor of usability and each variable of searching experiences. Searching experience deals with previous computer experience of the participants such as familiarity with information retrieval system, experience of computerized library catalogs, experience of commercial on lire databases and etc. In order to ex tract appropriate variables for searching experiences, many other existing questionnaires are examined. After careful examination, a few variables are extracted which are relevant with cataloger's daily work. In this study, searching experiences are referred a few factors such as the experience of assisting users, $\alpha$ perience of computerized databases, experience of computerized catalogs and etc.

Cataloging and metadata services traditionally enable catalogers or information professionals to retrieve approp riate records providing infor mat ion they need to create cataloging records 
to represent it ems in their own cdlections. A better system means easier access to clear data that facilitate retrieval of information appropriate to the creation of the new record. Thus, usefulness and ease of use may be the primary factors to evaluate regardless of the details of the system.

\subsection{Study Goals and Problem Statements}

The purpose of this study is to examine the usability of a current existing catabging and metada ser vices system.

Several study objectives have been establi shed:

1. To gain experience in conducting usability testing on an integrated cataloging and metadata services sy stem.

2. To foster the search for knowledge and understanding of integrated cataloging and metadata services sy stem.

3. To compare various measures of efficiency, effectiveness and satisaction across several var iation s of an integrated cataloging and met adata services system.

4. To investigate and evaluate the usability issues of an integrated cataloging and metadata services sy stem.

5. To determine how effectively the integrated cataloging and metadata services work in terms of usability issues.

This study also proposed to examine whether;

1) Effectiveness, efficiency and satisfaction from this test are relaed to participants' background status (educational status, searching experience etc.);

2) Overall usability from this study is related to partcipart s' background st dus (educational status, seardhing experience, etc.);

3) There are common features in the system that cause difficulties in users searching.

\section{Significance and Limitations of the Research Design}

Information systems, regardless of whom or what they serve, must reconcile performance with the needs of users. For several decades, information professionals have sought to achieve this goal by seeking ways to better satisfy their users. This study can add to a deeper understanding of the concept and role of meadata as it relaes 
Usability Assessment of an Integrated Cataloging and Metadata Services:an Exploratory Study of the OCLC Connexion System197

to the traditional concept and practice of cataloging. This study is limited to evaluating an integrated cataloging and met adata services system, and is also limted to assessing only those components that the Connexion system permits. Therefore, it will not be possible to address the usability issues of other standards and systems, or the role of different components in detail. Further, this study is limited to evaluating three usabilty factors: effectiveness, efficiency, and user satisfaction. Other fact or s such as system performance, cost, etc. are beyond the scope of the study.

\section{Review of the Related Literature}

\subsection{The Function of Metadata in the Library Environment}

Met adata contains the characteristics of and relationships within source data, allowing information seekers to obtain concise information about source data that may not be recorded in the source it self due to its nature (Desai 1990). The nature of metadata has been an intensey debated issue in the information communities. According to Desai (1997), metadata should meet several requirements if it is to be considered useful in the library and information field. For example, metadata should serve as an instrument for describing the semantic content of a resource, for supporting retrieval by content, and for expressing semantic dependencies that are inherent in a collection of objects. While the Web provides a convenient venue for publishing and disseminating information, it lacks a mechanism for negotiating a publicly shared agreement about the meaning of fundamental infor mation (Brasehvik 1998). For any metadata scheme, information professionals must decide which attributes to use, what each attribute means, and how it is to be instantiated and used. Just as with any knowledge representation scheme, a metadata scheme is subject to the user's perceived conceptualizaion of the domain to which the metadata statement $s$ refer (Gruber 1995). According to Wendler(Wendler 1999), cataloging can be considered metadata but not all met adata can be con sidered ca aloging. In addition, Wendler noted that many characteristics of electronic resources make them hard to describe, such as variability of presentation, unfamiliar form of issuance, ill- defined relationships 
to materials in other forms, mutability, mobilty, and absence of physical receipt. Disparate types of resources, then, must be assembled in a coherent information environment. Further, while simpler metadata for mats like Dublin Core have been developed catalogers should be able to understand how metadata standards can be executed in libraries in order to en rich the library's services.

\subsection{Information Overload on the Web and the Need for Metadata Standards}

The dramatic growth of electronic information resources has proven to be a tremendous challenge to effective access. First, the scope and quantity of information is increasing because more information is generated in digital for $m$ or" born digital." In addition, institutions and agencies are digitizing existing analog forms of resources. Publishing this information electronically is more cost- effective, and can potentially provide improved access for citizens (Mullen 2001). As Thornely (Thornely 1998) argued, the Internet needs to have a standardized way of descrbing resaurces to enhance the process of resource discovery, thus, we find the re- emergence of an old concept of cataloging in the new cyber era - metadata. According to Dempsey and Heery (Dempsey and Heery), it is inevitable that diverse approaches to metadata study will continue and new for mats will be created to fit new user communities and market opportunities.

Metadata involves many hundreds of different dh aract er istćs for bildiograph ic cataloging and related disciplines. Of these and hundreds of other descriptive metadata, however, just a few ch aracteristćs are almost always pe tirent to all information resources, such as title, author, subject, date, and place. These few characteristics are used traditionally for the citations of books and are the same characteristics now found in metadata on the World Wide Web. The use of these basic m aracteristis in a Web- based me adata system provides a foundation for common searching of the metadata regardless of the types and formats of the information being sought. Metadata schemes have the potential to more precisely organize electronic information, and can protect the ow nership of infor mation. Given the longstanding use of metadata in basic library cataloging, it stands to reason that librarians need to be meaningfully involved in this groundbreaking effort. 


\subsection{Further Research on Metadata}

Researchers have identified two directions for further study, both of which involve the creation of metadata systems for electronic documents. The first approach is to embed the met adata descriptions into the $\measuredangle H E A D>$ portion of an HTML document using the META tags. This is the easiest method for conveying the metadata information to the user. Weibel (1997) noted that this technique has several advantages. No additional system must be in place to use it, and because the metadata is integral to the resource it can be harvested by Web indexing agents. A second method for using met adata to organize electron ic resaurces involves creating a database to collect and manage metadata records. In this case, the metadata is not embedded in the resource itself, but is gener ated by the document owners and stored separately from the resource it describes in a Web database system. Another promising area for research concerns inter oper ability. Over five years ago, Tennant (Tennant 1997) studied interoperability, or the capacity of a user to treat multiple digital library collections as one. Tenn ant believed that inter operability was the key challenge facing digital libraries. Tenn ant (Tenn ant 2000) recently wrote of an effort to establish interoperability, the Open A rchives, an initiative aiming to specify the methods by which several various individual archives can interoperate. According to his previous article, he suggested that such inter oper ability can be achieved by specifying: a) a protocol for gathering or" harvesting" metadata from participating archives; b) a criteria to selectively harvest metadata; and c) a common metadata for mat for arch ives to use in responding to harvesting requests (Tennant 2000). In his book, Berners- Lee (Berners- Lee 1999) descr bed his notion of a Web populated with rich metadata that is machine- readable, semantically flexible, and derived from trusted sources. In a related vein, Medeiros (Medeiros 2000) argued that a trusted, structured mechanism is needed in order to parse context relationships across all semant ic schemes.

One alternative to a single system containing both Dublin Core and MARC was CORC, an OCLC research project desigred to provide cooper at ive catabging of electronic resources using a variety of metadata standards. U sers of CORC could choose to view records in either the Dublin Core or the MARC 
for mat. At the Met adata Preconference in 2000, Weibel (Weibel and Koch 2000) predicted that CORC would become the prism system for the Internet. Malone noted, however, that the requirement that participating libraries devote the equivalent of a half- time staff person to the project might prevent smaller librar ies from joining (Weibel and Koch, 2000).

A ccording to Heery and her coll eagues (Heery, Powell and Day 1998), inter operability can exist at a number of Ievels. From the user's point of view, interoperability can be more or less effective depending on how closely the various services are integrated in regard to semantics, query language, indexing, and management of results (Heery, Powell and Day 1998). Dempsey and Heery (Dempsey and Heery 1998) have noted that, metadata will assist indi iduals to more ffectively use existing resources and prove to be essential for effective systematic use of resources. From Dempsey's point of view, metadata must not merely be considered a tool for the organization of Internet information, but a form of knowledge th at allows automated as well as human users to behave intelligently.

\subsection{Usability}

With the unparalleled access to information made possible by the World Wide Web, library and information professionals now have a vast new information environment with which to support users. In addition to dealing with print materials, library work has come to include digitizing special collections, journals, and data sets as well as creating and managing online publ ic access catalogs (OPACS) and World Wide Web (WWW) sites. As Web services and content increase, the complex ity of the information options that must be digested and navigated by the user also increases (Palmquist 2001). Yet despite the ex plosion of infor mation tech nology and the growing depen dence on computer $\mathrm{s}$ throughout the world, it was not so long ago that librar ies began to devote ser ious attention and physical resources to the creation of Web sites (Battleson, Booth and Weintrop 2001). Aware th t the user is one of the most importart factors in the library and information science environment, information specialists have made a great effort to create easily usable Web- based interfaces and effective systems for communicating with users. One of the best ways to determine how well an 
Usability Assessment of an Integrated Cataloging and Metadata Services:an Exploratory Study of the OCLC Connexion System201

information sy stem performs is to measure its usability. In information sciences research, usability refers to the extent to which a user can negotiate a product or system quickly and easily in order to complete the tasks given to him or her. Accordingly, the concept of usability emphasizes the user's understanding of what he or she wants and needs to achieve (Veldof, Prasse and Mills 1999). As the features and functions of products that we use at home and in our workplaces become ever more complex, the ndion of usabilty becomes increasingly relevant. Above all, product designers must con sider the needs and limitations of users. Otherw ise products created with the intention of del ivering some benef it can end up being more trouble than they are worth. Users are becoming more sophisticated with respect to their expectations about product performance. These expedations include ideas about a product's desired usability (Landauer 1995). With the growth of the Internet, the usability of websites has become an increasingly important area of research as well. In the words of Palmquist (Palmquist 2001), "U sability is not a new idea, but its application to the Web is relatively new " (p.124).

Usability is one of the focuses of the Human- Computer Interaction $(\mathrm{HCl})$ field as well. As the name suggests, in Human- Conputer Interaction studies, usability refers to bridging the gap between the computer's capabilities and its use by an actual individual. The notion of usabilty is the primary concern of a great number of books, articles, w ebsites, conferences, and con sultants. U sability is also the focus of a class of ergonomics called user-centered design (UCD), or, in the realm of computers, human- conputer interaction $(\mathrm{HCl})$. In order for these systems to work well, users must be able to employ them effectively. The perceived usability of a system depends on a number of factors, including how well the functionality fits user needs, how well the application fits the user's task flow, and how well the reaction of the application fits user expedations.

Within Human- Computer Interaction $(\mathrm{HCl})$ circles, where use - centered design has been around for more than 20 years, the full meaning of usability extends bey ond a site's intuitive virtues. In his technical writings about usability, Nielsen (Nielsen 1993) provides one of the most complete definitions around, identifying five attributes of a usable interface:

1) easy to learn; 
2) efficient to use;

3) easy to remember ;

4) causes few errors; and

5) pleasant to use. (p.281)

Seen from an $\mathrm{HCl}$ persped ive, however, the notion of usability has a meaning other than" user- friendliress." Usabilty is rooted in cognitive science - the study of how people perceive and process information through learning, the use of memory, and attention (Head 1999). Usability experts like Nielsen, on the other hand, tend toward simpler categorizations of user differences. According to Nielsen (Niel sen 1995), simpler, less cognt ively or iented categor ies can be more easily identified and still account for a fairly large degree of performance variance even if a variety of fact ors may affect a user's per for mance.

\subsection{Usability Testing and Library and Information Science}

With the predominance of infor mation tech nology (e.g. tools, gadges, hardware, software, and program applications) in the library and information environment, infor mation professionals have begun to turn more to the evaluation of systems using usability testing. Because usability focuses on the users and an understanding of what they want and need to accomplish when they use the product, usability simply means that the people who use a product can complete their task quickly and easiy (Oulanov and Pajarilb 2001; Veldo, Prasse and Mills 1999).

Many studies of usabilty in the library and information environment have focused on end-user behavior in automated systems, online catalogs, networked databases, and CD- ROMs (Borgman 1996; Hert 1996; Nahl and Tenopir 1996). The overall focus of these studies has been the ease with which users are able to employ the tools at their disposal, and in what ways library systems can be improved to help users better achieve their aims. Other related usability studies have examined Web usability and user-computer interfaces. The LIS It erature also cont ains studies in which usabilty testing methods have been employed to assess users. This research has dealt with user fadors such as the human cognitive process in information seeking in the library and information environment.

Despite the relatively long history of studying and responding to user behavior through end- use studies, the relative lack of literature on the topic reveals that librar ies are only beginning 
to apply usabilty testing to their westes. Several studies have ex amined the use of library websites in order to $\alpha$ plore usability issues in the library and information field. Eliasen, McKinstry, and Fraser (Eliasen, McKinstry and Fraser 1997) tested students' ability to navigate on line menus and correctly seled dat abases from the library hom甲age at the Univer sity of Washington.

Within the last decade, researchers in library and information sciences, as well as other areas, have sought to adopt a user-centered approach to the investigaion of infor mation seeking behaviors and the development of better information tools (Dervin and Nilan 1986). Hjorland and Albrecht sen (Hjorland and Albrechtsen 1995) and Albrechtsen (A lbrecht sen 1993), for example, focused on the need for a use - cettered appr oach to the development of representational structures. They argued that the development of effective organizaional tools (such as indexes and thesauri) depends upon an analysis of language usage within a particular discourse community or knowledge domain. A I ibrary website, then, might be con sidered a complex application int egrating access to and interaction between a diverse set of information products and services and various user groups. Usabilty testing represents a means to ensure that the satisfaction of the user in the library setting can be achieved.

\subsection{Issues for Further Research on Usability Testing}

Although studies of metadata and usability testing do exist, researchers need to continue to address related issues for fur ther theor etical and applied development in both of these areas. In the words of Spool (Spool 1997), The Web is a whole new ball- game, and we' re still learning how to play. We don't know how to design for finding in for mat ion" (p.12). Veldof (Veldof, Prasse and Mills 1999) has argued that the ongoing application of usability testing in libraries is one way to ensure the development of electronic services and resources "chauffeured" by the user. Veldof's discussion was of fered in the hope that LIS (Library andInformation Sciences) faulty con sidering the prosped of developing usabilty courses or modules will find this information useful in furthering their ef forts. As the LIS field continues to improve an understanding of Web- based delivery of information services and resources, the effort to provide some degree of user testing can 
produce better Web- design effort. This clearly has been a high priority for many in the e-commerce and for-p pof it busiress community for a while. In the nonprof it sector as well, such as in libraries as well, the Web has given real meaning to the importance of applying usercentered design practice.

The Web certainy provides a valuable communication channel between the user and LIS professionals who seek to serve the user's infor mation needs from bey ond the physical environment of the library or information center. Web sites have become an integral part of the information access mission of academ ic libraries. It is challenging to develop a usable and effective site as well as maintain and redesign that site to meet the constantly changing needs of the user. Usabilty testing is very appropr iate for this task since it not only identifies use - inter face problems, but also suggests ways for attacking those problems. As Batteson (2001) arg ued, the importare and applicability of usability testing to library websites cannot be under st $₫ e d$. Whether through simple inspection, inquiry, or formal usability testing, libraries can employ usability testing methods to inform and evaluate design changes, especially as librarians strive to meet the increasing information demands of users.

Usability testing can lead library and information science professionals to better understand the user and make contributions as designers or trainers for nonprofit information services or for - profit information product developers (Palmquist 2001). Further, usability testing can be applied as an inex pen sive means for assessing important library systems and products, and the results can lend credibility to the creation or updating of more user-friendly library OPACs, websites, and the like (Walbridge 2000). Usabilty testing should be applied to all the many facets of the library and information environment because of this very premise. If barriers to effective information seeking are continuously con fronted and overcome, then infor mat ion professionals can feel satisfed that they are doing their jobs.

\section{Data Collection and A naly sis Methods}

The overarching goal of this study is to ex plore usabilty issues and problems related to integrated cataloging and met adata services.

U sability testing is established as a compounding of a variety of methods 
and techniques. Because methods of data collection and analysis should be correlated in order to answer research questions, researchers agree that the ideal approach is a combination of quantitative and qualitative methods.

\subsection{The System under Study: OCLC Connexion}

Connexion is a production system that was developed by OCLC to proide access to cataloging records through WorldCat, the world's largest on Iine union catalog and bibliographic database. Libraries use Connex ion to create and edit quality bibliographic and authority records, which help users find the maerials they need more quickly. Con nex ion facilitates sharing of records with the entire OCLC cooperative, which benefits libraries worldwide (http://www.oclc.org/ connexion/). Connexion combines the most useful features of OCLC's web browser- based system. OCLC Con nex ion is based on CORC, CatExpress, CatMe, and Passport, and the knowledge that OCLC has gained from working with users over many years. Connexion also automates input of data, and aligns records with the authoritative WorldC at database. First released in July 2002, Connexion provides general cataloging functionality for all types of library materials (Lindlan and Mering 2002). Connexion reflects OCL C's intention to take the best features of each of the aforement ioned tools and integrate them into the new calabging service. According to OCLC, Connexion is OCLC's flagship cataloging service, a powerful, flex ible suite of tools with built- in access to WorldC $d$, the world's largest bibl iog raph ic dat abase. The Con nex ion provides several mechanisms for getting in; the main menu composed of five different search options with a few sub categories (see $<$ Figure 3.1 $>$ ). Such a variety of options is helpful when dbserving user s' diver se interactions with the system.

The purpose of the Connexion system is to provide an integrated cataloging service to its members. Thus, the primary users are cat aloging experts who catalog materials on a daily basis. Therefore, it would be fair to state that Connexion's

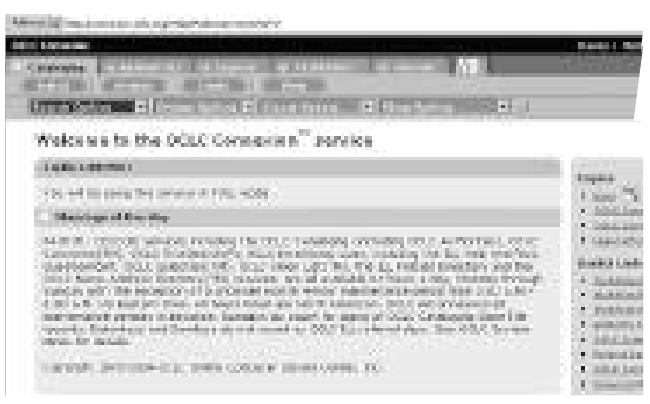

Figure 3.1> Homepage of the OCLC Connexion (http://connexion.oclc.org/) 
representative users are mainly those who work in general area of ctaloging, including faculty teaching cataloging classes, catalogers, and technical services librarians.

\subsection{Data Collection}

A thought provoking question in usability testing is: What number of subjeds will be sufficient for this study? Generally, it is assumed that the major advantage of usability testing is that very few test subjects are actually required. According to $\mathrm{Nielsen}$ (Nielsen 1989, 1993) approximately five subjects may uncover roughly $90 \%$ of the global usability problems inherent in any design. However, the proper" number of required test subjects for establishing a minimum level of staistcal confidence in usability testing is often a source of controversy.

In the Tallahassee area, where there are approx imately 12- 15 cataloging experts in the field, and this research recruited 10 of them for the test. Participants were recruited throughout the Tallahassee are by letter. The invitation letters were sent to all local cataloging related sectors. A $\$ 10.00$ honorar ium was of fered for participation. All of the subjects participated on a voluntary basis.

A total of 10 cataloging experts participated in the study, 6 women and 4 men. Most of the participants know how to use commercial on line databases such as Dialog or FirstSearch even if they do not use them in a daily basis. Only one participant had never used OCLC Passport or Connexion. However, it turned out from the test that most of them have used Passport or other products of OCLC raher than Con nexion.

The pre- seach questionnaire gathered information about the participants' computing and searching experience. Their searching experience with different information systems ranged from 1 to 7 ( 1 = Never; 2 = Once a year; $3=$ Quarterly; $4=$ Once a month; $5=$ Once a week; $6=2$ to 3 time a week; $7=$ Daily) with a mean of $6.10 \mathrm{SD}=.59161$ ). In detail, the participants declared that they had the most $\alpha$ perience with Search Engies ( $M=6.80, S D=.422)$, Computerized Library Catalogs $(\mathrm{M}=6.80, \mathrm{SD}=.632)$, OCLC Passport or Con nexion ( $M=5.60$, $S D=2.271$, and had the least $\propto$ perience in Commercial online databases $(\mathrm{M}=$ $5.20, S D=1317$ ), in that order. It is of particular value to note that most participants have experienced a var iety of databases and infor mation retrieval systems and they rated them selves as 
better than intermediate users.

There were four phases for the test: pretest phase, introduction, testing phase, and debriefing phase. All the sessions were videotaped with the participants' consent. The entire test for each participant took about an hour in general.

$<$ Table 3.1> Participants Profile

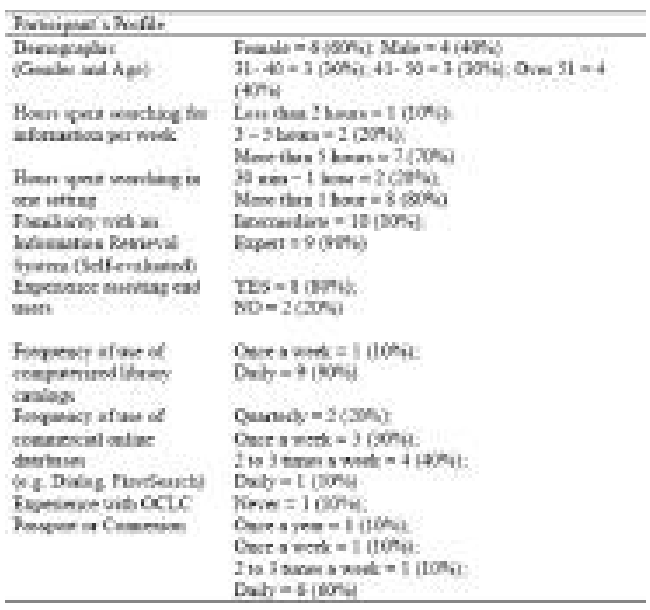

\subsubsection{Tasks}

Two important things were con sidered in the design of these searching tasks. First, the tasks should reflect the users' real information needs in their workplaces. Second, the type of the tasks was considered. For this reseach, Spool's task types were adapted to create four tasks as well as careful review of cataloger's daily work.
A set of four tasks was created (See $<$ Table 3.2>) based on these two consider at ions. Tasks 1 and 2 were jud ged to be simple fact-finding questions and tasks 3 and 4 were considered as the questions asking a comparison and judgment from the users. Tasks 1 and 2 were to find a book record using the infor mation provided by the question. For tasks 3 and 4, the participants were expected to find a few records which would help in creating a catalog record related to the topic and to make a judgment from the records they found. In addition to the consideration of the task types, Task 3 also included searching different format of metadata, in this case online resources.

$<$ Table 3.2> Types of Questions, Topics and Provided Tasks

\begin{tabular}{|c|c|c|}
\hline $\begin{array}{l}\text { Cantin } \\
\text { Tyx }\end{array}$ & Dqw & Tank \\
\hline $\begin{array}{l}\text { Singlo bact } \\
\text { fals. }\end{array}$ & $\begin{array}{l}\text { Soveded } \\
\text { beik } \\
\text { wain }\end{array}$ & 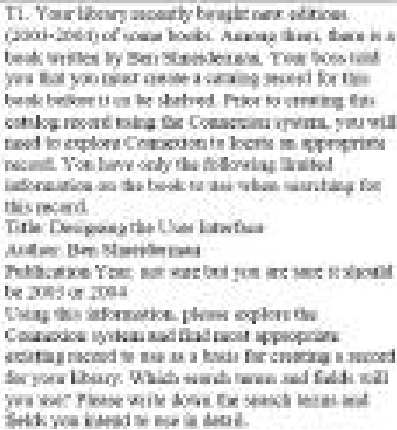 \\
\hline
\end{tabular}




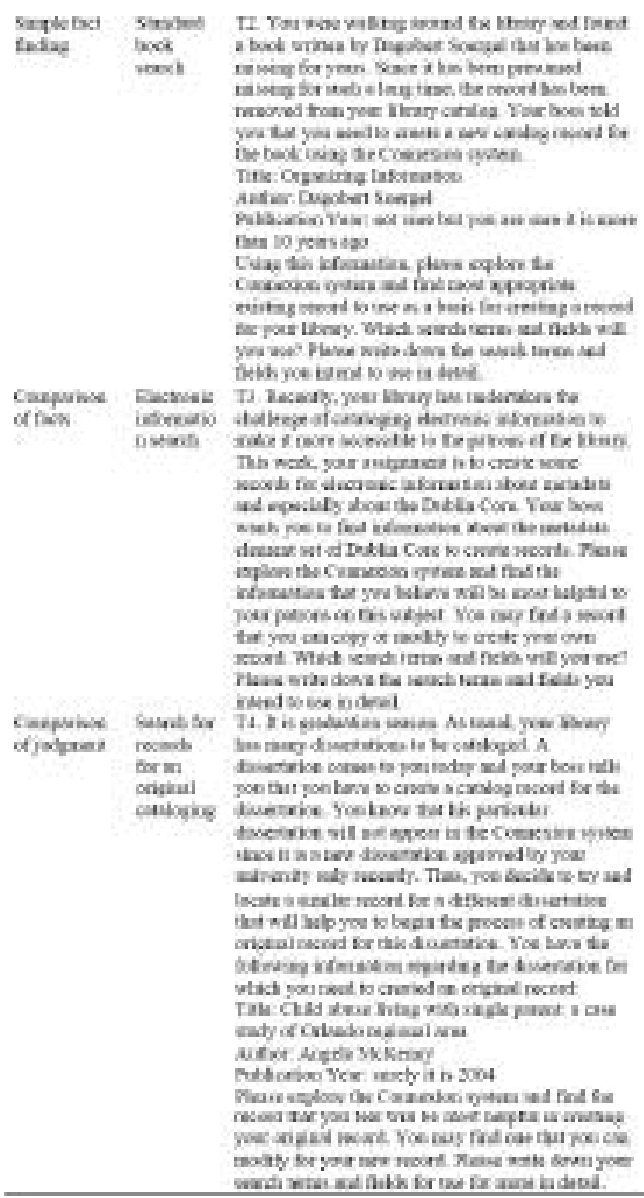

\subsection{Introduction to the Data Analy sis}

$<$ Table 3.3> contains data collection, methods of data analysis, and a result presentation for each research question. Content Analysis and Classification method is used to analyze the qual itative data gathered from videotaped records, recorded think-aloud remarks, and videotaped logs of the participants' interaction with the system.

$<$ Table 3.3> Data Collection and Analysis Methods

\begin{tabular}{|c|c|c|c|}
\hline $\begin{array}{l}\text { Danavet } \\
\text { Cornten }\end{array}$ & Date Cabouse & Drafantra & Dusedutica \\
\hline KQ: & Acwersey and & Constingo & $\begin{array}{l}\text { Freson'y Compinon } \\
\text { ylusis }\end{array}$ \\
\hline 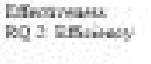 & 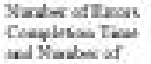 & Candiriste & 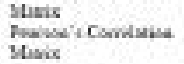 \\
\hline ho + Seminesce. & 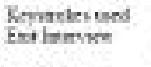 & $\begin{array}{l}\text { Deverethr } \\
\text { Soriviks: }\end{array}$ & $\begin{array}{l}\text { Dremprre betion } \\
\text { Tes. }\end{array}$ \\
\hline $8 Q+$ Clabuly of & IFuctwasen. & Devirgen: & Dnowpars susases \\
\hline 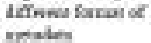 & Errinucyad & Serivats & Talds \\
\hline kQ5 & 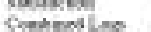 & Center & 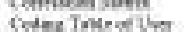 \\
\hline Idenifemono od & and Erithovinn & Ansyosent & Fasgove of Untairn \\
\hline rivuafication ef & & Clawity & Doblesexasd \\
\hline Cuboins & & Olakiry & Climsticiniea Irole of \\
\hline $\begin{array}{l}\text { Pildern id at } \\
\text { Comenge }\end{array}$ & & Petimat & Veders Pottien \\
\hline
\end{tabular}

\section{Data Analysis and Results}

\subsection{Overview of Collected Data}

Accuracy and number of errors are evaluated to measure effectiveness. Participants who spent more time in one setting ten ded to get bet er accuracy rates and participants who thought they were more familiar with an information retrieval system made fewer errors during this research.

Efficiency was measured by evaluating completion time and the number of keystrokes used in this test by each participant. Participants who thought they were familiar with information retrieval systems in general tended to 
use less time and fewer keystrokes to complete their tasks.

The satisfaction measures included participants exit interview responses as reported on a 1 to 9 Likert Scale. Only one experience that of working with computerized library catalogs, had significant relationships with easy of use and understandability, but it did not seem to affect overall satisfaction.

Among the three main categories, effectiveness and efficiency seem to have been related in some ways but the satisfaction measure were not dependent with either effectiveness or efficiency. Ccorrelation matrices were provided for usabilty in searching different meadat a for mats.

A content analysis was performed after identification and classification of usability problems, and the results were presented. Seventeen coded usabilty problems were divided into six classifications, which were in turn presented and analyzed.

\subsection{Effectiveness, Efficiency and Satisfaction}

In order to see the reld ion sh ips bet ween the three measures, another Pearson' $\mathrm{s}$ correlation analysis was conducted. As presented in $<$ Tables $4.7>$ through
$<$ Table 4.1> Pearson's Correlations between Effectiveness and Efficiency $(\mathrm{N}=10)$

\begin{tabular}{|c|c|c|c|}
\hline $\begin{array}{l}\text { Rouedvat } \\
\text { Coniens }\end{array}$ & Den Caloave & Dra fablysi & Doneatica \\
\hline $\begin{array}{l}\text { KQ: } \\
\text { Sforosanu }\end{array}$ & $\begin{array}{l}\text { Acruney and } \\
\text { Xad ar effryoss }\end{array}$ & Constinse & $\begin{array}{l}\text { Freson'y Complaven } \\
\text { Yusis }\end{array}$ \\
\hline $\mathrm{RQ} 2 \mathrm{EF}$ Enesy & 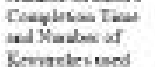 & Candistin: & 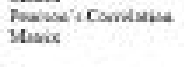 \\
\hline $\mathrm{ha}+$ seminenot & Eatimmer & 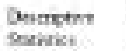 & $\begin{array}{l}\text { Drserme bevenon } \\
\text { Tust }\end{array}$ \\
\hline 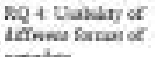 & 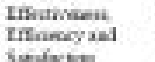 & $\begin{array}{l}\text { Devirgewn } \\
\text { Sorkrict }\end{array}$ & 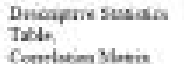 \\
\hline inos & 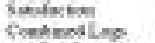 & cerre & 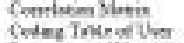 \\
\hline Idenifemoso ed & and frothovirn & Anatrosend & Foogrine of Uhatirn \\
\hline $\begin{array}{l}\text { Daboles } \\
\text { Dowat }\end{array}$ & & $\begin{array}{l}\text { Clusaty } \\
\text { Ounary }\end{array}$ & 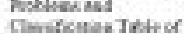 \\
\hline 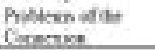 & & Avilum & Viveder Putters \\
\hline
\end{tabular}

$<$ Table 4.2> Pearson's Correlations between Effectiveness and Satisfaction $(\mathrm{N}=10)$

\begin{tabular}{|c|c|c|c|}
\hline & Dwed suticforsen & Accurst & Nhoibse of eman \\
\hline 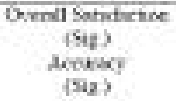 & 3 & $\begin{array}{c}35 \\
6255 \\
1\end{array}$ & $\begin{array}{l}-122 \\
(756) \\
-354 \\
\operatorname{cons}\end{array}$ \\
\hline 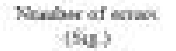 & & & 1 \\
\hline
\end{tabular}

* Correlation is significant at the 0.05 level (2-tailed). ** Correlation is significant at the 0.01 level (2-tailed). (Sig.) Significance level

$<$ Table 4.3> Pearson's Correlations between Efficiency and Satisfaction

$$
(N=10)
$$

\begin{tabular}{|c|c|c|c|}
\hline & Qranll Setifactase & Taxs & Kesitroken \\
\hline 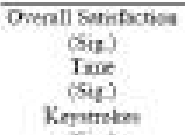 & 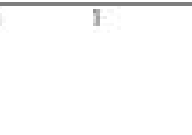 & $\begin{array}{c}-376 \\
\{.265) \\
1\end{array}$ & $\begin{array}{c}+47) \\
6.179 \\
442 \\
(241) \\
1\end{array}$ \\
\hline
\end{tabular}

$<$ Table 4.9>, only effectiveness and efficiency show in between correlations. 
However, accuracy is independent from all other factors. Among three measures such as effectiveness, efficiency and satisfaction, the satisfaction measure appears to be independent from others, which means satisfaction is not related to any effectiveness or ef ficiency fact ors.

\subsection{Identification and Classification of Usability Problems}

From the combined logs, the participants' perceptions of usability problems were coded. Coding rules were set prior to coding. Problems caused by a simple mistaken dick or typing error, etc. were not included in the coding. The code covered only problems that resulted from some feature or function of Connexion itself. For example, one of the participants was trying to use the Pathfincer" option rather than the "Search" option for Task 1 She was not conscious of her mistake because the option was set to" Pathfinder." That mistake was caused by a clicking error during her exploration of the interface at the beginning. She said " what am I doing?‥it looks so different from what I want to do"...(and looking at the researcher and she said"' I didn' t mean to $\cdots$ I thought I was under the
Search option." This kind of problem is elimirated from usabilty problem coding. From the combined logs and the exit interview data, a total of 172 usability problems were found. Among them, 17 unique usability problems were identified. Following identification, the usability problems were classified with reference to several areas of Con nex ion features, in order to summarize overall usability problems.

More problems were found in Task $1(n=38)$ and Task $3(n=37)$, as compared to Task $4(n=26)$ and Task $2(n=14)$. The usability problems found in Task 2 are mostly duplicated in Task 1 since the tasks are very similar in type.

The top six most frequently found usability problems were;

4 The error message is not easily recognized;

u Only one term per one search box seems inconvenient;

( Q Quick tips are too vague or not specific enough;

u It is hard to understand the terminology or syntax;

4 Help is not helpful; and

( Options for manipulation of results are limited. 


\subsection{Usability Problems}

Based on the identification of usabilty problems in the test, six areas are emerged in the classification of usability problems. The six areas are: User Assistance, Error Prevention and Correction, Color and Visual Clarity, Navigation, Information Grouping and Structure, and Language Usage. Summary of the problems of the each area was provided from the following.

Usability problems in user assistance.

$<$ Table 4.4> Usability Problems in User Assistance

Unability Roblreas is Uher Anistance

Qrick hps are too rapue or act spacific eovugh (UP II)

Help s noe helpfol (UP io)

Lacix of monction os bow w nue each opeco (UP 03 )

Lack of explasorion of the min orions on the top (UP 0L)

Two of the problems were about lack of information on options. The examples include" I am curious about what the main option can do for each $\cdots$ about what Pahfiner means". (Participant 005) Help and Quick tips are the other two codes identified in this area. These areas are \$pecifd and helpful enough when the cataloger had been trained well before using the Con nexion . However, when they were not æcustomed to use Connexion frequently, even a skillful cataloger showed irritation.
Usability problems in navigation.

$<$ Table 4.5> Usability

Problems in Navigation

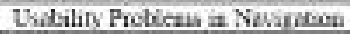

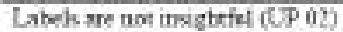

It ss hrd to whervind the orginizing schene (UP 04)

The submein is heod to fite had lecks descrogtica (UP 65)

Autheriny files ace very cumbersome aed conforing (UP 10)

The locaticu of uesceh is welear (UP 07)

The navigation area is central to the actual searching process of the test. The most important problem is summed up by this statement." It's hard to understand how to do something." For example, one participant said," I was under" Cataloging" and there are

"Search, Browse, Create and Show" options $\cdots$.. thought I was using Search since that option was what I was used for Task 1 and for searching the WorldCat database, but suddenly a different interface came and I found out I was in a different d丸abase. (Loking at the researcher, he grumbles) I went too far, I guess."(Participant 101) Usability problems in information grouping and structure.

This area is related to the final resuts structure because it contains features which might affect the final result and the manipulation of it. As may be seen in $\langle$ Table 4.6>, two of the problems are about final resut and the man pulation 
of it. For example," I got more than 80 electronic records. Wow '..it's too many. OK, is there anything to help me set the limit using this set? Somehing. putting more keywords or...oh oh.. I think they don't, (looking at the researcher) Do they ?" (Participant 009)

Too many complicated field option buttons are another usability problem coded in this area. Sometimes, it is helpful for users to have access to as many field options as the information sy stem developer can provide. However, sometimes having too many brings difficulties of use. For example," I am using Keyword searching. OK, what kind of options do I have? Author, title, LCSH, Library of Congress Classifcation Number $\cdots$ There is another search option, using numer ic numbers on ly, right under this keyword search $\cdots$ They may want to cut and simplify these options. It is taking long time to find the right option and click it." (Participant 006)

$<$ Table 4.6> Usability Problems in Information Grouping and Structure

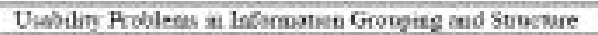
Limitel oplices Sor mintgalision of sevils (UP 14)

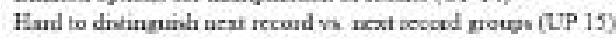

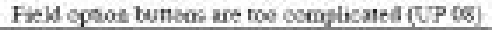

Usability problems in color and visual clarity.
Two usability problem codes were classified into the Color and Visual Clarity area $<$ Table 4.7>. For example, " I may be out of the line but they could use different colors for different searching options. Every part has the same color, blue or navy, whatever... It looks consistent but it is little bit confusing - hard to know which one I am using". (Participant 009)

$<$ Table 4.7> Usability Problems in Color and Visual Clarity

Unability Rroblems in Color and Visual Claraty Reading is difficult (UP (6))

Feames for ench search opsions are too semilar (UP 09)

Usability problems in error prevention and correction.

Two usability problem codes were designated in the Error Prevention and Correction area of the system. For example," In Task 1, I made two errors. I didn't know what I did wrong. After the two errors, I saw the message on the top of the keyword search option part saying I have to use m ly one key word in each box. I also noticed that it was in the Quick Tips a long time Ia er when I was doing Task 3. This is not good. Most other infor mation ret rieval systems let the user put in more than two ter ms. 
Usability Assessment of an Integrated Cataloging and Metadata Services:an Exploratory Study of the OCLC Connexion System213

I think I am too used to using a general information system rather than a cataloging systems." (Participant 005) $<$ Table 4.8> contains the usळilty problems in Error Prevention and Correction.

$<$ Table 4.8> Usability Problems in Error Prevention and Correction

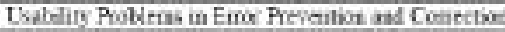
The eroc mesclage is ont easily feco mized (UP 17 )

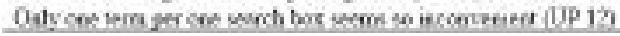

Usability problems in language usage.

There is one usability problem code in the Language Usage area as presented in <Table 4.9>. For example," I read the Quick Tips and typed something in the command search. It didn't work. I have used another cataloging system. It seems to be using different words... or am I confused?' (Participant 005)

$<$ Table 4.9> Usability Problems in Language Usage

Usubiliry Problemw as Language Uhage

Hand to understand the terminology or syntax

\section{Conclusions and Implications}

\subsection{Overall Results}

Effectiveness is related to participant s' familiarity with information retrieval sy stems. Other fad ors such as experience of computerized library catalogs, experience of search engires, experiences of OCLC Passport or Connexion, etc. are not related with effectiveness in this test. This conclusion leads toward another discussion on training and learning issue in integrated cataloging and me adata systems, wh ich is addr essed in this paper.

Efficiency is related to familarity with the information retrieval systems both in completion time and number of keystrokes used in this test. Partciparts who thought they were familiar with infor mation retrieval systems in general tended to use less time and fewer keyst rokes to complete their tasks. Other factors of searching experience were not significant in this test. A careful decision was made that familiarity with information retrieval systems is the one most important factor related to both effectiveness and efficiency. This also leads to another discussion on learning issues within integrated cataloging and metadata systems, which will be found later.

There is only one experience, that of computerized library catalogs, which has shown significant relationship with easi ress and under st an dbi ify sat i seact ion 
measures. This relationship was not shown with regard to overall saisfaction. This means that the participants who felt Connexion was easy and un der stan dable did not necessariy feel comfortable and satisfied in this test. Regading those resuts from ef fectiveness and efficiency, it appears that even for those participants who felt Con nex ion was easy and under stancable, the most powerful factor was familiarity with information retrieval system. The experience with computerized library catalogs helped the participants to feel more at ease with understanding Connexion, but this did not effect their searching. Those who had been used to computerized library calogs knew what the ordinary features of a cataloging system might be, but there was no evidence in the tests that this helped the participants to be effectiveness and efficient in searching. Once again, this finding has implications for learning and training.

Th rough this study, 17 coded usaility problems of con sider ation were develped. Six classiféd usabilty problems containing the 17 usabilty problems were presented and analyzed. Connexion should make improvements in at least six of those areas in order to be more usable as an integrated cataloging and metadata system for its primary audience.

In terms of Error Prevention and Correction, there is a need for more easily recogniz Đle messages for users. A pop- up window letting users know that they have made a mistake and should correct it would be most useful. Generally, a somewh at more simplified structure would be helpful for Navig a ion and Information Grouping \& Structure; perh aps more obv ious color different iat ion among options would prevent some errors. Finally, instructions and explanations of each option need to be improved to reduce the costs of training and searching the database.

\subsection{Implications for the Connexion Usability}

The int eg rated catabging and meadat a system, Connexion, used in this study is still changing. OCLC is planning to quit other services such as Passport and services will be integrated into a single service using Connexion (http://www . odc. og/cm nex ion / $\mathrm{m}$ i gat ing /effault . ht m).

In order to serve better to its users, OCLC will need to implement two recommendations arising from this study .

First, there need to be major cø rection s made to the interface of Connexion. 
Usability Assessment of an Integrated Cataloging and Metadata Services:an Exploratory Study of the OCLC Connexion System215

Most important among these are improving the user assistance and navig tion aspeds. Searching and creating catalogs are activities that are essential to intellectual work in Library and Information Studies. More useful instruction and explanation of the interface will help to reduce searching efforts and save in training costs.

Second, the training for Connexion use needs to be redirected and refocused. Current training focuses on the features of the Connexion without placing these in the context of searching. Training only in the features of the Connexion is not currently enough for learning to make a better search in Connexion. Users also need to be trained in every asped of the infor mation retrieval system to increase their understanding of how such sy stems work. The results of this test demonstrate that users who were already familiar with information retrieval systems more satisfied with Connexion. The continued development of Connexion and its fur ther integration with other databases affords a unique opportunity for such improvements to be implemented.

\subsection{Usability issues}

The results of this study provide two suggestions for usability studies of a cataloging system.

First, used along the effectiveness by completion time is a problematic in evaluating cataloging systems. In order to get the correct record, a cataloger searches through databases and make decisions regarding which record is the proper one for his/her work. It is clear that completion time is directly related to the type of task the searcher engages in (simple fact finding vs. judgment task). Cataloging work, for example, is always subed to the decisonmaking process, deciding whether a record is right or wrong, and therefore completion time may not be the best measure for evaluating the usability of a cataloging system. Therefore, completion time should be split into two categories; time taking to search the information and time taking to evaluate and make a judgment especially when it used a measure of usability testing with cataloging systems.

Second, results of this study suggest that developers of cataloging systems need to be more active in soliciting and supporting usability studies designed to test the usability of the particular sy stem for particular users. There have been many usability studies that test usability of a system in general as 
described in this paper. There have also been usabilty studies of specifd met adata systems. However, there have been no studies specifically designed to test the usability studies of cataloging and metadata systems for catalogers, their primary user population. It would be adv isळle to move the foars of usabilty testing into more specific systems at this point, with specific users in view.

\subsection{Future Research Directions}

The findings of this study provide a platform for expansón and establishment of a future research agenda.

First of all, testing of all $₫$ her cur rently existing cataloging systems is necessary comparison with integrated cataloging and met adata systems. Such ef forts may support generalization of the results of this study. In addition, such ef forts may provide better and more detailed understanding of usability problems encountered in cataloging systems.

Since the usabilty studies are grounded in user behaviors, it would be interesting to investigate these, with the goal of establishing possible models of specific user-group behaviors in our field, especially those of catalogers.

During the test, individuals used various numbers of keywords. Some used only two or three, but others used more than six keywords, including all the qualifiers located in the option box. An interesting topic for future research w ou ld be to see if calogers demon st rate consistent patterns of keyword usage.

For future study, it would be recommended to carefully consider the task types and arrangement of the tasks. In order to solve this problem, it would be recommen ded to adapt a few different sets of similar types of tasks to see the differences in terms of the types of tasks.

Last, but not least, the study of catabgers searching behavior is another interesting topic for future research. During this test, catalogers preferred to use Command search or Derived Search when they thought they knew how to use them. There are many infor mation ret $r$ ieval systems and search engines currently in popular use and more will certainy be developed for a wide range of user groups. Study of catalogers' searching behavior might provide illuminating contrast with the searching behavior of ordinary endu sers. 


\subsection{Conclusion}

The goal of this study was to examine usability issues and to uncover where an integrated cataloging and metadata system lay the usability problems of its primary users, catalogers.

This research started by looking at three usability measures and their relation to users' searching experience, and went on to examine the usability problems that Connexion, an integrated cataloging and metadata system was faced with.

This study showed that the most importart asped of usabilty in Con nexion is the users' prior experience with an information retrieval system. Also, it showed there are seventeen usability problems with Con nexion, and that these can be grouped into six categories.
Needless to say, it is most important to note that usability is not an exclusive goal of such an integrated cataloging and metadata system. Other goals such as quality of cataloging records, and the reliability of its cataloging and met adata system are equally its concer $n$.

This study also suggested testing on more diverse cataloging systems and their use by specifo user groups, especaly catalogers, would be beneficial to increasing our understanding of the role that integrated cataloging and metadata system will play. Although application of the recommendation of this study will improve the usability of the Connexion system for its primary use group, much work remains to er sure that as this system develops its user s are well served. 


\section{References}

Battleson, B., Booth, A. and Wein trop, J. 2001." Usability testing of an academic library Web site: a case study at SUNY Buffalo". The Journal of Academic Librarianship 27, 188- 198.

Berners- Lee, T. 1999. Weaving the Web: The Original Design and UItimate Destiny of the World Wide Web by Its Investor. HarperSanFrancisco, CA:San Francisco.

Borgman, C. L. 1996“" Why Are Online Catalogs Hard to Use? "Journal of the American Society for Information Science, 47, 493504.

Brasethvik, T. 1998." A semantic modeling approach to me adata." Internet Research, 8, 377- 386.

Burnett, K. M. and Lee, J.- M. 2000. Met adata Development Update, in, ASIS Annual Meeting 2000, Chicago.

Burnett, K. M., Ng, K. B. and Park, S. 1999." A comparison of the two traditions of metadata development." Journal of the American Society for Information Science, 50, 1209-
1217.

Campbell, N. 2001 Usabilty A ssessment of Library-Related Web Sites: Methods and Case Studies. Usabilty Assessment of LibraryRelated Web Sites: Methods and Case Studies (N. Campbell, ed.) LITA a divison of American Library Association, Chicago and London.

Chapman, A. 2002." Demystifying Met adata." Catalogue \& Index, Winter, 1- 6.

Dempsey, L. and Heery, R. M. 1998.

" Metadata (a current view of practice and issues." Journal of Documentation, 54, 145172.

Dervin, B. and Nilan, M. 1986. "Information needs and uses. Annual review of information science and technology," NY: Knowledge Industry Publs.

Desai, B. C. 1990. Introduction to database systems. St. Paul, MN: West.

Desai, B. C. 1997:. Supporting discovery in virtual libraries(two proposed in dex metadata structures for indexing and supporting search 
and discovery: the Dublin Core Elements List and the Semantic Header." Journal of the American Society for Information Science, 48, 190204.

Eliasen, K., McKinstry, J. and Fraser, B. M. 1997". Navigaing online menus: a quantitative experiment at the University of Washington." College \& Research Libraries, 58, 509516.

Gluck, M.1996. "Exploring the Relationship between user satisfaction and relevance in information systems." Information Processing \& Management,32, 56- 73.

Gray, M. 1997. Growth in the number of Web sites, in, Retrieved September 19, 1999, from ht tp: //w w w . mieds/peole/mkgr ay /net/.

Gruber, T. 1995." Toward principles for the design of ontologies used for knowledge sharing? "International Journal of Human- Computer Studies, 43, 907- 928.

Head, A. J. 1999. Design Wise: A Guide for Evaluating the Interface Design of Information
Resources. Medford, NJ: Information Today, Inc. Heery, R., Powell, A. and Day, M. 1998." Met adata: CrossROA DS and Inter oper ability." A riadne (Online) 14, 3- 6.

Hert, C. A. 1996." User Goals on an Online Public Access Catalog." Journal of the American Society for Information Science, 47, 504- 518.

Hjorland, B. and Albrecht sen, H. 1995. " Toward a new horizon in information science: domainanalysis." Journal of the American Society for Information Science, 46, 400425.

ISO, DIS and 9241- 11 1994. Ergonom ic Requirements for Office Work with Visual Display Terminals, Part 11: Guidance on Usability, in, International Standards Organizaion, London.

Janes, J. W. 1994." Other people's judgments: A comparison of users' and others' judgments of document relevance, topicalty, and utility." Journal of the American Society for Information Science, 45, 160171.

Landauer, T. K. 1995. The trouble 
with computers: usefulness, usability, and productivity . Cambridge, MA: MIT Press.

Lindlan, K. and Mering, M. 2002.

" OCLC Connexion: Cataloging after OCLC Passport." Cataloging Service Bulletin, 63- 64.

Medeiros, N. 2000." Features $X M L$ and the Resource Description Framework: The Great Web Hope." Online (Weston, Conn.), 24, 37- 40. Milstead, J. L. and Feldman, S. E. 1999." Metadata: Cataloging by Any Other Name." Online (Weston, Conn.), 23, 24- 50.

Mullen, A. 2001." GILS metadata initiatives at the state level: Gover $n$ ment Infor mat ion Loca or Services." Government Information Quarterly, 18, 167180.

Nahl, D. and Tenopir, C. 1996. A ffect ive and Cognitive Searching Behavior of Novice End- Users of a Full- Text Database." Journal of the American Society for Information Science, 47, 276- 286.

Nielsen, J. 1993. U sability Engineering. Cambridge, MA: Academ ic Press. Nielsen, J. 1995. Multimedia and hypertext: The Internet and beyond. Cambridge, MA: A cademic Press

OCLC 2000. The Web Charaderizaion Project. Retrieved November 11, 2002, from http://wcp. oclc. org.

OCLC 2003. OCLC Researchers estimæe 1- percent decrease in size of public Web. Retrieved May 14, 2003, from ht tp: //w w w . dcc. org/reseach /an noun cements/2003- 02- 26.m. Oulanov, A. and Pajarillo, E. J. Y. 2001. Usability evaluation of the City Univer sity of New York CUNY + da abase. The Electronic Library, 19, 84- 92.

Palmquist, R. A. 2001“ An Overview of Usability for the Study of Users' Web- Based Infor mation Retrieval Behavior." Journal of education for library and information science, 42, 123136.

Sh abajee, P. 2002. Primary multimedia objects and 'educational metadata': a fundamental dilemma for developers of multimedia archives." D- Lib Magazine, 8, 16.

Spod, J. M. 1997. Web Site U sability: A Designer's Guide. North 
Andover, MA: User Interface Engineering.

Tennant, R. 1997:" Digital Libraries.” Library Journal, 122, 31- 34.

Tennant, R. 2000." Open archives: a key conver gence." Library Journal, 125, 122- 123.

Veldof, J.R., Prasse, M. J. and Mills, V. A. 1999: Chauffeured by the User: Usability in the Electronic Library." Journal of library administration, 26, 115140.

Walbridge, S. L. 2000. Usabilty testing and libraries: the WSU experience: Washington State Univer sity. Alki, 16, 23- 24.

Weibel, S. 1997،" The 4th Dublin Core metadata report." D- Lib Magazine, 3, 12.

Weibel, S. and Koch, T. 2000." The Dublin Core metadata init iat ive: mission, current activities, and future directions." D- Lib Magazine, 6, 21- 24.

Wendler, R. 1999." Branching O ut: Catabging Skills and Functions in the Digital Age." Journal of Internet Cataloging, 2, 43- 54.

Wh t eside, J., Ben nett, J. and Holtzblatt, K. 1988. Usabilty Engineering: Our Experience and Evolution, in M. Helan der, (ed.), H andbook of Human Computer Interaction, New York, NY: North Hdland. Zmud, R. W. and Boynton, A. 1991. Survey measures and instruments in MIS: Inventory and appraisal. in K. L. Kraeme , (ed.), The information systems research challenge: Survey research methods (pp.149-184). Bost n, MA: Harvard Business School. 